\title{
EXIGÊNCIAS CLIMÁTICAS PARA O DESENVOLVIMENTO E MATURAÇÃO DOS FRUTOS DE CULTIVARES DE COFFEA ARABICA $\left({ }^{1}\right)$
}

\author{
MARCOS RAFAEL PETEK $\left({ }^{2 *}\right)$; TUMORU SERA $\left({ }^{3}\right)$; INÊS CRISTINA DE BATISTA FONSECA $\left({ }^{4}\right)$
}

\begin{abstract}
RESUMO
O objetivo foi caracterizar as exigências climáticas dos estádios fenológicos de cultivares de C. arabica e indicá-las para a tecnologia de escalonamento da colheita. As avaliações foram realizadas na fazenda experimental do Instituto Agronômico do Paraná (IAPAR), em Londrina, em 16 genótipos, segundo uma escala fenológica, durante dois anos. O número médio de dias, a soma térmica em graus-dia, a precipitação pluvial acumulada e a temperatura média da florada até o estádio de maturação completa (cereja) foram, respectivamente, de 226,2 $\pm 15,3$ dias, $2.781 \pm 143,5$ graus-dia, $1.065 \pm 149,2 \mathrm{~mm}$ e $22,49 \pm 0,47^{\circ} \mathrm{C}$. Foi possível caracterizar, de acordo com a exigência térmica, as cultivares Icatu Precoce IAC 3282, Mundo Novo IAC 464-12, IAPAR 59, Rume Sudam IAC 1139 e Costa Rica 95 como precoces; as cultivares Catucai 785-15, Catucaiaçu, Villa Sarchí ICAFÉ, Rubi MG1192 e Ouro Verde IAC H5010-5, como de maturação média; as cultivares 'Obatã IAC 1669-20', Sarchímor IAPAR88480-8, Tupi IAC 1669-33, 'Catuaí Vermelho IAC 99', 'Catucai Vermelho 4-79' e ‘Sarchímor E9702 III-1-9’ como tardias. Com base em análises de regressão foi possível determinar e quantificar a influência da disponibilidade hídrica para os estádios fenológicos de chumbinho, expansão, grão verde, verde cana e, conseqüentemente, a duração da florada até o estádio cereja. A ocorrência de deficiências hídricas acelera a maturação dos frutos, pois diminuem as necessidades térmicas para a maturação dos frutos em café arábica.
\end{abstract}

Palavras-chave: Café, escalonamento da colheita, graus-dia, desenvolvimento dos frutos

\section{ABSTRACT \\ CLIMATIC REQUIREMENTS FOR FRUIT DEVELOPMENT AND RIPENING OF COFFEA ARABICA CULTIVARS}

\begin{abstract}
The aim of this research wAS to determine the thermal requirements in degree-days for sub-phases of fruit development in arabic cultivars and to indicate those genotypes for scalonated harvesting. This research was carried out at the experimental farm of the Agronomic Institute of Paraná (IAPAR), in Londrina, state of Paraná, Brazil. Each plant was evaluated at 15 to 20 days intervals from August 2004 to August 2005 (harvest 2004/05) and from August 2005 to August 2006 (harvest 2005/06), according to a phenological scale of fruit development. The average number of days, the thermal requirements in degree-days, the accumulated precipitation and the average temperature to reach the stadium of complete maturation (cherry) were, respectively, $226.2 \pm 15.3$ days, $2781 \pm 143.5$ degree-days, $1065 \pm 149.2 \mathrm{~mm}$ and $22.49 \pm$ $0.47^{\circ} \mathrm{C}$. It was possible to characterize the genotypes by their thermal needs as follows: the cultivars Icatu Precoce IAC 3282, Mundo Novo IAC 464-12, IAPAR 59, Rume Sudam IAC1139 and Costa Rica 95 as early maturation; the cultivars Catucai 785-15, Catucaiaçu, Villa Sarchí ICAFÉ, Rubi MG1192 and Ouro Verde IAC H5010-5, as intermediate maturation; the cultivars 'Obatã IAC 1669-20', Sarchímor IAPAR88480-8, 'Tupi IAC 1669-33', 'Catuaí Vermelho IAC 99', 'Catucai vermelho 4-79' and Sarchímor E9702 III-1-9 as late maturation. By using regression analyses it was possible to determine and quantify the influence of water supply in different phenological stages. The occurrence of water deficiencies accelerated maturation, therefore, reduced the thermal necessities for fruit maturation in Arabic coffee.
\end{abstract}

Key words: Coffee, scalonated harvesting, degree-days, fruit development.

(1) Recebido para publicação em 5 de outubro de 2007 e aceito em 20 de agosto de 2008.

$\left({ }^{2}\right)$ Embrapa Soja, Caixa Postal 231, 86001-970 Londrina (PR). E-mail: mrpetek@cnpso.embrapa.br $\left(^{*}\right)$ Autor correspondente.

$\left({ }^{3}\right)$ Instituto Agronômico do Paraná, Área de genética e Melhoramento de Café, Caixa Postal 481, 86047-902 Londrina (PR). E-mail: tsera@iapar.br

$\left({ }^{4}\right)$ Universidade Estadual de Londrina, Centro de Ciências Agrárias, Departamento de Agronomia, Caixa Postal 6001, 86051-990 Londrina (PR). E-mail: inescbf@uel.br 


\section{INTRODUÇÃO}

A cafeicultura é uma atividade agrícola bastante competitiva, portanto, novas tecnologias que visam proporcionar aumento de rentabilidade, por meio da diminuição de custos e melhorias na produtividade e qualidade, pelo uso adequado de cultivares, são sempre valiosas. Tecnologias simples de serem utilizadas e que não implicam aumento de custos para o cafeicultor, utilizando cultivares com épocas de maturação diferenciadas, são a colheita escalonada e A recomendação regional/local de cultivares (Sera e Guerreiro, 1994; Sera, et al., 2002; Pereira et al., 2002; Garçon et al., 2001; Matielo e Almeida, 2001).

Nas cultivares de café arábica disponíveis no mercado há diferenciais quanto à maturação dos frutos, porém foram classificadas em condições edafoclimáticas inerentes aos locais onde foram selecionadas. Sabe-se que, apesar da precocidade de maturação dos frutos ser controlada geneticamente (CARVAlHo, et al., 1991), essa característica é bastante influenciada pelas condições edafoclimáticas regionais, microclimáticas e sistemas de cultivo. Variações regionais e interanuais na fenologia de cultivares de café podem ocorrer devido às diferenças edafoclimáticas entre regiões de cultivo. Como conseqüência, podem não concretizar aqueles diferenciais esperados na maturação dos frutos.

Dentre os elementos climáticos, a temperatura do ar, que atua na duração do ciclo reprodutivo, é considerado o mais relevante (Pezzopane et al., 2003). Portanto, caracterizar as exigências térmicas das cultivares de café arábica para completar o ciclo fenológico, com o uso do conceito de graus-dia, pode ser importante ferramenta na identificação de cultivares com diferentes épocas de maturação.

O conceito de graus-dia se baseia no fato de que a taxa de desenvolvimento de uma espécie vegetal está relacionada à temperatura do meio (PEREIRA et al., 2002). A caracterização dos estádios fenológicos por meio da soma térmica, pode proporcionar uma uniformização da classificação das cultivares em grupos de maturação, já que existem divergências encontradas na literatura. A cultivar Catuaí Vermelho IAC 81, por exemplo, classificada e registrada como de maturação média a tardia no Estado de São Paulo (FAzUoli et al., 2002), recebeu outras classificações, como, maturação tardia (SERA e Guerreiro, 1994), intermediária a precoce (GARÇON et al., 2001) e média (FERRÃo et al., 2001).

O ciclo fenológico do cafeeiro é bastante extenso, conseqüentemente, sujeito a significativas diferenças climáticas dentro de uma mesma florada, portanto, é preciso analisar cada estádio fenológico e identificar suas interações com as variáveis climáticas.

Segundo Camargo e Camargo (2001), o ciclo fenológico do cafeeiro arábica pode ser divido em seis fases distintas, durante dois anos. O primeiro ano fenológico, considerado o período vegetativo, é formado por uma fase inicial de vegetação e formação de gemas florais, de setembro a março, e outra fase de indução e maturação das gemas florais, de abril a agosto. O período reprodutivo, durante o segundo ano fenológico, inicia-se pelo estádio da florada. Após a queda das flores, um período de aparente dormência, mas com intensa atividade celular, denominada chumbinho, tem duração de 6 a 8 semanas (CANNELL, 1985; SAlazAr-Gutièrrez et al., 1994). O estádio de expansão dos frutos, caracterizado por rápido aumento em volume e massa seca, com alta demanda hídrica, formará o tamanho da semente e tem duração até a $16 .^{\mathrm{a}}$ ou $17 .^{\mathrm{a}}$ semanas após a florada. Aproximadamente 200 dias após o florescimento (Arcila-Pulgarín et al., 2002) ou em torno da 32. ${ }^{a}$ semana (CANNEll, 1985), inicia-se o processo de maturação dos frutos, primeiramente, tornando-se verde amarelo (verde cana) e atingindo a maturidade fisiológica ou estádio cereja, em torno de 240 dias depois do florescimento (SALAZAR-GuTIÈRREZ et al., 1994; Arcila-Pulgarín et al., 2002).

O objetivo deste trabalho foi classificar cultivares de C. arabica por grupo de precocidade de maturação e caracterizar as exigências climáticas para os estádios fenológicos, visando indicá-las para a utilização nas tecnologias de escalonamento da colheita e recomendações regionais e locais.

\section{MATERIAL E MÉTODOS}

Este estudo foi realizado no Centro de Produção e Experimentação de Londrina, do Instituto Agronômico do Paraná, em condições de campo, em solo do tipo Latossolo Vermelho distroférrico, com temperatura média anual de $20,8^{\circ} \mathrm{C}$, altitude de 585 metros, latitude $23^{\circ} 22^{\prime}$ Sul e longitude $51^{\circ} 10^{\prime}$ Oeste. Os genótipos utilizados estão descritos na tabela $1 \mathrm{e}$ estão instaladas no campo em blocos, contendo de 15 a 30 plantas.

As avaliações foram realizadas em intervalos de 15 a 20 dias, durante o período de agosto de 2004 a agosto 2005 (safra 2004/2005) e de agosto de 2005 a agosto de 2006 (safra 2005/2006), segundo a escala fenológica proposta por Pezzopane et al. (2003), sendo: 0 = gema dormente; 1 = gema entumecida; $2=$ abotoado; 3 = florada; 4 = pós-florada; 5 = chumbinho; $6=$ expansão dos frutos; $7=$ grão verde; $8=$ verde cana; 9 = cereja; $10=$ passa; $11=$ seco. Em cada 
avaliação foram atribuídas três notas da escala fenológica para cada planta de cada bloco, abrangendo o estádio fenológico das três principais floradas. O estádio fenológico considerado para cada genótipo, a partir de cada florada, foi a nota com maior repetividade (moda) em cada avaliação. Os dados de temperatura utilizados para os cálculos de graus-dia e os dados de precipitação foram obtidos do Instituto TeCnOlógico - Simepar (2005). Foram determinadas as datas de início e fim dos estádios a partir de cada florada para cada genótipo. As variáveis consideradas neste estudo foram:

Número de dias necessários para os estádios de chumbinho (D/C), expansão (D/E), grão verde (D/ $\mathrm{GV})$, verde cana $(\mathrm{D} / \mathrm{VC})$ e da florada até o estádio de cereja (D/F-CE);

Soma térmica em graus-dia para os estádios de chumbinho (GD/C), expansão (GD/E), grão verde $(G D / G V)$, verde cana $(G D / V C)$ e da florada até o estádio de cereja (D/F-CE);
Temperatura média durante os estádios de chumbinho (T/C), expansão (T/E), grão verde (T/GV), verde cana $(\mathrm{T} / \mathrm{VC})$ e da florada até o estádio de cereja (T/F-CE);

Precipitação pluvial acumulada para os estádios de chumbinho $(\mathrm{P} / \mathrm{C})$, expansão $(\mathrm{P} / \mathrm{E})$, grão verde $(\mathrm{P} / \mathrm{GV})$, verde cana $(\mathrm{P} / \mathrm{VC})$ e da florada até o estádio de cereja (P/F-CE).

O cálculo da soma térmica em graus-dia (GD) e o valor diário (Gdi) foram obtidos, conforme citado por Pezzopane et al. (2005), pelas relações:

$G D i=$ Tmed $_{i}-T b$ em que: Tmed é a temperatura média do ar no dia i e Tb é a temperaturabase, considerada $10,5^{\circ} \mathrm{C}$;

$$
G D A=\sum_{i=1}^{n} G D i \text { em que: GDA é a soma térmica }
$$
em graus-dia durante um período.

O vigor vegetativo $(\mathrm{V})$ de cada planta do ensaio foi avaliado segundo uma escala de 1 a 10 , sendo: $1=$ planta amarela com abundante seca de ramos e $10=$ planta verde-escura com abundante ramificação.

Tabela 1. Comparação entre médias de cinco ciclos fenológicos para número de dias (D/F-CE), graus-dia (GD/F-CE), precipitação pluvial (P/F-CE) e temperatura (T/F-CE), da florada ao estádio de cereja de 16 genótipos de café arábica. Anos agrícolas de 2004/2005 e 2005/2006. IAPAR, Londrina (PR)

\begin{tabular}{|c|c|c|c|c|}
\hline Genótipos $\left({ }^{1}\right)$ & $\mathrm{D} / \mathrm{F}-\mathrm{CE}$ & GD/F-CE & $\mathrm{P} / \mathrm{F}-\mathrm{CE}$ & $\mathrm{T} / \mathrm{F}-\mathrm{CE}$ \\
\hline Icatu Precoce IAC 3282 & 205,0 a & $2.587 \mathrm{a}$ & $1.005 \mathrm{a}$ & 23,18 a \\
\hline Mundo Novo IAC 464-12 & 207,4 a & $2.622 \mathrm{a}$ & 994 a & 23,21 a \\
\hline IAPAR 59 & 210,6 a & $2.650 \mathrm{a}$ & $1.014 \mathrm{a}$ & 22,99 a \\
\hline Rume Sudam IAC 1139 & 216,6 a & $2.707 \mathrm{a}$ & $1.054 \mathrm{~b}$ & $22,77 \mathrm{~b}$ \\
\hline Costa Rica 95 T-8667 & 216,6 a & $2.707 \mathrm{a}$ & $1.054 \mathrm{~b}$ & $22,72 \mathrm{~b}$ \\
\hline Catucai 785-15 & $223,6 \mathrm{~b}$ & $2.762 \mathrm{~b}$ & $1.056 \mathrm{~b}$ & $22,55 \mathrm{c}$ \\
\hline Catucaiaçu & $227,0 \mathrm{~b}$ & $2.779 \mathrm{~b}$ & $1.061 \mathrm{~b}$ & $22,63 \mathrm{~b}$ \\
\hline Villa Sarchí ICAFÉ & $227,6 \mathrm{~b}$ & $2.787 \mathrm{~b}$ & $1.049 \mathrm{~b}$ & $22,17 \mathrm{c}$ \\
\hline Rubi MG1192 & $227,6 \mathrm{~b}$ & $2.794 \mathrm{~b}$ & $1.078 \mathrm{~b}$ & $22,19 \mathrm{c}$ \\
\hline Ouro Verde IAC H5010-5 & $229,0 \quad b$ & $2.804 \mathrm{~b}$ & $1.065 \mathrm{~b}$ & $22,35 \mathrm{c}$ \\
\hline Sarchímor IAPAR 88480-8 & $232,8 b$ & $2.845 \mathrm{c}$ & $1.101 \mathrm{~b}$ & $22,16 \mathrm{c}$ \\
\hline Tupi IAC 1669-33 & $234,2 \mathrm{~b}$ & $2.859 \mathrm{c}$ & $1.104 \mathrm{~b}$ & $22,10 \mathrm{c}$ \\
\hline Catuaí Vermelho IAC 99 & $237,6 \mathrm{~b}$ & $2.874 \mathrm{c}$ & $1.080 \mathrm{~b}$ & $22,31 \mathrm{c}$ \\
\hline Catucai vermelho $4-79$ & $239,8 \mathrm{~b}$ & $2.886 \mathrm{c}$ & $1.082 \mathrm{~b}$ & $22,22 \mathrm{c}$ \\
\hline Sarchímor E9702 III-1-9 & $239,8 \quad b$ & $2.893 \mathrm{c}$ & $1.082 \mathrm{~b}$ & $22,32 \mathrm{c}$ \\
\hline Obatã IAC 1669-20 & $243,6 \mathrm{~b}$ & $2.935 \mathrm{c}$ & $1.151 \mathrm{~b}$ & $22,08 \mathrm{c}$ \\
\hline Média \pm DP $\left({ }^{2}\right)$ & $226,2 \pm 15,3$ & $2.781 \pm 143,5$ & $1.064 \pm 149,2$ & $22,49 \pm 0,47$ \\
\hline Média $\pm \mathrm{DP}^{\mathrm{a}}\left({ }^{3}\right)$ & $211,2 \pm 12,7$ & $2.655 \pm 135,2$ & $1.004 \pm 188,1$ & $23,12 \pm 0,31$ \\
\hline Média $\pm \mathrm{DP}^{\mathrm{b}}\left({ }^{4}\right)$ & $232,9 \pm 17,5$ & $2.785 \pm 163,3$ & $1.078 \pm 126,9$ & $22,71 \pm 0,45$ \\
\hline Média $\pm \mathrm{DP}^{\mathrm{c}}\left({ }^{5}\right)$ & - & $2.882 \pm 123,2$ & - & $22,25 \pm 0,53$ \\
\hline $\mathrm{CV}_{\mathrm{e}}(\%)$ & 4,99 & 3,39 & 4,99 & 1,66 \\
\hline
\end{tabular}

( $\left.{ }^{1}\right)$ Médias de genótipos seguidas pela mesma letra não diferem entre si pelo método de Scott e Knott a $5 \%$ de probabilidade. DP = desviopadrão; $\mathrm{CV}_{\mathrm{e}}=$ coeficiente de variação experimental. $\left({ }^{2}\right)$ Média e desvio-padrão geral. $\left({ }^{3}\right)$ Média e desvio-padrão dos genótipos classificados com letra a. $\left({ }^{4}\right)$ Média e desvio-padrão dos genótipos classificados com letra b. $\left({ }^{5}\right)$ Média e desvio-padrão dos genótipos classificados com letra c. 
O potencial de produção $(\mathrm{P})$ de cada planta foi avaliado visualmente em litros de fruto cereja/ planta, levando-se em consideração o tamanho dos grãos, número de frutos por roseta e quantidade de rosetas frutificadas. A produtividade em litros de fruto cereja por planta (litros/planta) foi transformada para produtividade/ha $(\mathrm{P})$ com base no número de plantas/ha (pl/ha), segundo a expressão: $\mathrm{P}=$ (litros/ planta $\times \mathrm{pl} / \mathrm{ha}$ ) / 500 (500 é um valor médio em litros de café da roça para se obter uma saca de café beneficiado).

Para comparar as variáveis obtidas entre os genótipos foram realizadas análises de variância e testes de médias de Scott e Knott, em que cada florada foi considerada como uma repetição. Foram consideradas três floradas da safra 2004/2005 (26/ $9 / 2004,21 / 10 / 2004,24 / 11 / 2004)$ e duas de $2005 /$ 2006 (04/9/2005 e 25/9/2005). A terceira florada da safra 2005/2006 não foi considerada, pois foi pequena e a ocorrência de outras floradas pouco depois (dezembro de 2005 e janeiro de 2006) impossibilitaram sua distinção. As características vigor vegetativo e produtividade foram analisadas por meio da análise de variância, considerando-se cada ano como uma repetição.

Foram realizadas análises de regressão simples considerando-se cada florada como uma amostra, dentro de cada grupo de genótipos separados pelo teste de médias e considerando todos os genótipos do experimento. A variável graus-dia em cada estádio e do período da florada até cereja foi considerada como dependente e a variável precipitação pluvial acumulada nos mesmos períodos foi considerada variável explicativa. Cada uma das cinco floradas de cada cultivar foi considerada como amostra. Todas as análises estatísticas foram realizadas com o programa estatístico Genes (CRUZ, 2001; CRUZ, 2006).

\section{RESULTADOS E DISCUSSÃO}

Os genótipos utilizados neste estudo formam boa representatividade do material genético utilizado comercialmente na cafeicultura Brasileira, bem como dos países produtores de café da América Central (Tabela 1). As médias para número de dias (D/F-CE \pm DP (desvio padrão)), soma térmica em graus-dia (GD/F-CE \pm DP (desvio padrão)), precipitação acumulada (P/F-CE \pm DP (desvio padrão)) e temperatura média em ${ }^{\circ} \mathrm{C}(\mathrm{T} / \mathrm{F}-\mathrm{CE} \pm \mathrm{DP}$ (desvio padrão)), da florada até o estádio de maturação completa (cereja) foram, respectivamente, $226,2 \pm 15,3$ dias, $2.781 \pm 143,5$ graus-dia, $1.065 \pm 149,2 \mathrm{~mm}$ e 22,49 $\pm 0,47^{\circ} \mathrm{C}$ (Tabela 1 ). O número de dias médio variou de 205,0 a 243,6 (Tabela 1) e está de acordo com o estabelecido por CARVALHO et al. (1991) para a espécie C. arabica, os quais obtiveram número de dias da florada à maturação dos frutos variando de 210 a 250, com uma média de 230 dias. A produtividade média dos genótipos foi de $25,99 \mathrm{sc} /$ ha e o vigor vegetativo médio foi de 7,56 , sem diferença significativa entre eles, pela análise de variância. Portanto, essas duas variáveis não influenciaram na duração do período fenológico da florada à maturação.

A cultivar mais precoce foi a 'Icatu Precoce IAC 3282', com 205 dias e soma térmica de 2.587 graus-dia da florada até o estádio de cereja (Tabela 1). Porém, não foi detectada diferença significativa entre esta cultivar e 'Mundo Novo IAC 464-12', 'IAPAR 59', 'Rume Sudam IAC1139' e 'Costa Rica 95' para graus-dia (Tabela 1).

Aguiar et al. (2004) indicaram várias linhagens de "Mundo Novo" como de maturação média, porém, não avaliaram a 'Mundo Novo IAC 46412 ', que pode ser um pouco mais precoce. IAFFE et al. (2001) obtiveram para a cultivar Mundo Novo IAC $379 / 19,237$ dias em média do florescimento à colheita, gerando uma soma térmica de 2.642 grausdia. Pezzopane et al. (2005) obtiveram também para a cultivar "Mundo Novo", não especificando a linhagem, 221 dias e 2.761 graus-dia do florescimento à maturação. Nesta pesquisa foi obtido para a 'Mundo Novo IAC 464-12', 207,4 dias do florescimento ao estádio de cereja, com soma térmica de 2.622 grausdia (Tabela 1), indicando ser esta uma cultivar de "Mundo Novo" com maturação mais precoce, nas condições do local do experimento.

Morais et al. (2005) obtiveram para a cultivar IAPAR 59, 173 dias e 2.302 graus-dia, diferente dos resultados constantes neste estudo com a mesma cultivar, que foi de 210,6 dias e 2.650 graus-dia. Os autores discutiram no trabalho que a maturação foi acelerada devido à deficiência hídrica, excesso de temperatura e ocorrência de cercosporiose, esta última, indicativo de cafeeiros mal nutridos e, portanto, de menor vigor vegetativo, indicando que estas variáveis, quando não homogêneas, podem levar a classificações errôneas de cultivares com relação à maturação dos frutos em café arábica.

A soma térmica em graus-dia para a cultivar Obatã IAC 1669-20, a mais tardia, foi 2.935 em 243,6 dias, o que significa uma necessidade térmica de 428,1 graus-dia maior para alcançar o estádio cereja, comparando com a 'Icatu Precoce IAC 3282' (Tabela 1). Os genótipos Sarchímor IAPAR88480-8, 'Tupi IAC 1669-33', 'Catuaí Vermelho IAC 99', 'Catucai vermelho 4-79 4-79' e a seleção E9702 III-1-9 ("Sarchímor") não diferiram estatisticamente da 
'Obatã IAC 1669-20'. Portanto, formam o grupo das cultivares mais tardias, variando de 2.845 a 2.935 graus-dia (Tabela 1). Estes resultados discordam de Aguiar et al. (2004) que indicaram a 'Tupi IAC 166933 ' como precoce, igual a 'Icatu Precoce IAC 3282'.

Os dados apresentados na tabela 1 demonstram a possibilidade de separar um grupo intermediário de necessidade térmica do florescimento à cereja. Os genótipos Catucaí 785-15, Catucaiaçu, Villa Sarchí ICAFÉ, Rubi MG1192 e Ouro Verde IAC H5010-5 revelaram necessidade térmica em graus-dia variando de 2.762 a 2.804 , formadoras, portanto, do grupo de maturação média (Tabela 1).

O número de dias da florada ao estádio de cereja (D/F-CE) separou as mesmas cultivares formadoras do grupo precoce, de acordo com o conceito de graus-dia (Tabela 1). Porém, aqueles genótipos separados, pela necessidade térmica, em médio e tardio, foram classificados no mesmo grupo de maturação de acordo com o número de dias (Tabela 1), indicando a eficiência do conceito de graus-dia em caracterizar a maturação de genótipos de café.

Com relação à precipitação pluvial acumulada entre os estádios de florescimento e cereja, as cultivares Icatu Precoce IAC 3282, Mundo Novo IAC 464-12 e IAPAR 59 representaram valores significativamente inferiores às demais e para temperatura média no mesmo período as cultivares revelaram valores mais elevados que as demais, em ambos os casos não ocorreram diferenças entre si (Tabela 1). Esse fato ocorreu devido a essas cultivares serem as mais precoces e, conseqüentemente, terem acumulado menos precipitação pluvial. Já, com relação às temperaturas maiores, o estádio cereja foi atingido antes dos meses mais frios.

Os desvios-padrão (DP) estimados dentro de cada grupo de maturação para graus-dia da florada até o estádio de cereja (Tabela 1) indicam a existência de variação entre as floradas, mesmo depois de considerar o efeito da temperatura utilizando o conceito de grausdia (GD/F-CE). Constata-se que existe outra fonte de variação, além da temperatura, que está influenciando na duração do ciclo fenológico dos genótipos. Devese, então, atentar ao fato de que o conceito de graus-dia leva em conta somente o fator térmico, não considerando o efeito de outras variáveis ambientais sobre o crescimento vegetal (PEREIRA et al., 2002).

A variação existente entre floradas, representada pelos desvios-padrão (Tabela 1), para graus-dia e precipitação acumulada da florada até a maturação completa (estádio cereja), possibilita analisar a influência das variáveis climáticas na duração deste período.
As análises da regressão entre a soma térmica em graus-dia (GD/F-CE) e a precipitação pluvial acumulada (P/F-CE), no período da florada até o estádio de cereja, foram significativas pelo teste $\mathrm{F}$ para os grupos de maturação precoce $(\mathrm{P}=0,01)$ e tardio $(\mathrm{P}=0,05)$ (Tabela 2). O grupo de cultivares com maturação média não foi significativo para a regressão, porém, na inclinação da reta observou-se o mesmo sinal dos demais grupos, indicando a possibilidade de analisar a regressão como todos os genótipos conjuntamente. A estimativa da inclinação da regressão foi de 0,7362 e o coeficiente de determinação, de $38,81 \%$ (Tabela 2), ou seja, a variação existente em precipitação pluvial acumulada explica $38,81 \%$ da variação existente em graus-dia. O sinal positivo da inclinação indica que a diminuição da precipitação acumulada diminui a necessidade térmica em graus-dia da florada ao estádio cereja, ou seja, acelera a maturação dos frutos. A estimativa do intercepto, que foi de 1.997,2, juntamente com a estimativa de inclinação da regressão (Tabela 2), significa uma necessidade de 73,62 graus-dia menor a cada $100 \mathrm{~mm}$ a menos de precipitação pluvial. É uma relação linear, dentro dos valores máximos $(1.319,1 \mathrm{~mm})$ e mínimos $(643,6 \mathrm{~mm})$ obtidos neste estudo, podendo existir respostas diferenciadas com precipitações pluviais acumuladas além destes limites. Portanto, dentre os elementos climáticos, a temperatura do ar, que atua na duração do ciclo reprodutivo, é considerada a mais relevante (Pezzopane et al., 2003), influenciando nos processos fisiológicos das plantas e interferindo em cada subperíodo de seu ciclo (BRUNini et al. 1976). Porém, não se deve considerar o conceito de graus-dia isoladamente e sim em conjunto com a disponibilidade hídrica. Segundo SigueIra et al. (1985) a deficiência hídrica é a outra variável climática que pode influenciar decisivamente na duração dos estádios fenológicos do café.

Segundo Jaramillo e GuZmán (1984) outro fator, além da temperatura, influencia no crescimento e no diâmetro dos frutos da cultivar Caturra, pois obtiveram somas térmicas diferentes entre floradas. SALAZAR-GUTIËRREZ et al. (1994) relacionaram o acúmulo de graus-dia, a quantidade de luz solar e a evapotranspiração com a taxa de acúmulo de matéria seca, nos frutos da cultivar Colômbia e indicaram a soma térmica como a variável que menos influenciou, durante o ciclo reprodutivo.

A quantificação da influência da temperatura do ar e da disponibilidade hídrica, na maturação dos frutos, é de extrema importância para o entendimento das relações clima-planta, bem como, a indicação regional precisa de cultivares baseada em precocidade de maturação dos frutos. 
Tabela 2. Resumos das análises de regressão e estimativas de intercepto, inclinação da reta e coeficiente de determinação

$\left(\mathrm{R}^{2}\right)$ entre graus-dia (GD) como variável dependente e a precipitação pluvial acumulada (P) como variável independente, durante os estádios de chumbinho (C), expansão (E), grãos verdes (GV), verde cana (VC) e da florada até o estádio de cereja (F-CE). Anos agrícolas de 2004/2005 e 2005/2006. IAPAR, Londrina ( PR)

\begin{tabular}{|c|c|c|c|c|c|c|c|}
\hline & \multicolumn{2}{|c|}{ Desvio } & \multicolumn{2}{|c|}{ Regressão } & \multicolumn{3}{|c|}{ Estimativas } \\
\hline & ‘G.L. & Q.M. & G.L. & Q.M. & Interc. & Inclin. & $\mathrm{R}^{2}(\%)$ \\
\hline F-CE & 78 & 863693,53 & & $17454,55 * *$ & 1997,17 & 0,7362 & 38,81 \\
\hline $\mathrm{F}-\mathrm{CE}{ }^{\mathrm{a}}$ & 23 & 8155,89 & & $251386,90 * *$ & 2008,15 & 0,6312 & 57,27 \\
\hline $\mathrm{F}-\mathrm{CE}{ }^{\mathrm{b}}$ & 23 & 19652,72 & 1 & $188335,68^{\mathrm{ns}}$ & 2023,39 & 0,7176 & 29,41 \\
\hline $\mathrm{F}-\mathrm{CE}{ }^{\mathrm{c}}$ & 28 & 10400,93 & & 148927,93 * & 2292,38 & 0,5360 & 33,83 \\
\hline C & 78 & 11758,86 & & 7118730,96 ** & $-138,82$ & 2,2385 & 88,59 \\
\hline $\mathrm{C}^{\mathrm{a}}$ & 18 & 3348,02 & 1 & 1486252,49 ** & $-115,90$ & 2,2033 & 96,10 \\
\hline$C^{b}$ & 58 & 14725,18 & & $5505772,25 * *$ & $-149,68$ & 2,2562 & 86,57 \\
\hline $\mathrm{E}$ & 78 & 38872,71 & 1 & 4351978,44 ** & 434,76 & 1,3870 & 58,94 \\
\hline GV & 78 & 33350,51 & & 3181916,51 ** & 501,88 & 1,4034 & 55,02 \\
\hline $\mathrm{GV}^{\mathrm{a}}$ & 53 & 27199,22 & 1 & $2424319,89 * *$ & 470,88 & 1,3907 & 62,71 \\
\hline $\mathrm{GV}^{\mathrm{b}}$ & 23 & 41547,25 & & 702924,16 ** & 578,51 & 1,3964 & 42,38 \\
\hline VC & 78 & 5821,06 & 1 & 164306,45 ** & 159,34 & 0,9501 & 26,57 \\
\hline
\end{tabular}

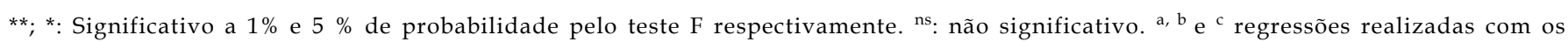
genótipos separados pelas letras a, b e c, respectivamente, pelos testes de médias (tabelas 1, 3, 4, 5 e 6).

A caracterização de cultivares de café por meio de graus-dia, considerando sempre a disponibilidade hídrica no período, poderá proporcionar uma uniformização das classificações quanto à maturação dos frutos em café arábica e evitar classificações divergentes, como a que ocorre com a cultivar Catuaí Vermelho IAC 81, que recebeu diferentes classificações conforme as regiões (FAZUOLI et al., 2002; SERA e GUERREIRO 1994; GARÇON et al., 2001; FERRÃo et al., 2001).

O desenvolvimento fenológico do cafeeiro, da florada até a maturação plena (estádio cereja) é formado por quatro estádios fenológicos, a saber: chumbinho, expansão dos frutos, grão verde e verde cana (CAMARGO e CAmargo 2001; Pezzopane et al., 2003). É importante analisar em cada estádio quais as influências das variáveis climáticas e quais estádios são responsáveis pelos diferenciais em maturação entre as cultivares apresentadas na tabela 1 .

O conhecimento dos estádios fenológicos do cafeeiro e suas interações com variáveis climáticas é fundamental para organizar as práticas de manejo como a aplicação fertilizantes, controle de pragas, doenças e planta daninhas, bem como o uso eficiente da tecnologia de escalonamento da colheita (ArCILAPulgarín et al., 2002).

Foram obtidos, para o estádio de chumbinho dos genótipos caracterizados, número de dias médio de $68,97 \pm 27,5$, o que significou uma soma térmica de $828,3 \pm 346,8$ graus-dia, com uma precipitação pluvial acumulada de 432,1 $\pm 146,0 \mathrm{~mm}$ (Tabela 4) e temperatura média no período de $22,27 \pm 0,99^{\circ} \mathrm{C}$. As cultivares Icatu Precoce IAC 3282, Mundo Novo IAC 464-12, IAPAR 59 e Catucai 785-15 exigiram exigência térmica e número de dias significativamente inferiores das demais, com relação ao estádio de chumbinho (Tabela 3). Essas cultivares, menos a 'Catucai 785-15', foram aquelas com menores exigências térmicas para alcançar o estádio de cereja, ou seja, foram as mais precoces. Esse fato demonstra, juntamente com o coeficiente de correlação significativo e positivo entre a necessidade térmica para o estádio de chumbinho (GD/C) e do período da florada ao estádio cereja (GD/ F-CE) (Tabela 7), a influência deste estádio fenológico na duração do ciclo fenológico reprodutivo ou do período florada-cereja.

Os desvios-padrão (DP) estimados para grausdia e precipitação acumulada durante o estádio de chumbinho nos dois grupos de cultivares, separados pelo teste de médias (Tabela 3), demonstram a existência de alta variabilidade para estas duas variáveis entre as floradas. A partir desta variabilidade existente foram realizadas as análises de regressão entre a soma térmica em graus-dia (GD/ C) e a precipitação $(\mathrm{P} / \mathrm{C})$ acumulada durante o período (Tabela 2), em cada grupo de maturação e de todos os genótipos em conjunto. Nas análises de desvios das regressões houve significância $(P=0,01)$ dentro de cada grupo de maturação (Tabela 2), demonstrando existir alta influência da disponibilidade hídrica para completar o estádio de 
chumbinho. Os sinais positivos das inclinações das retas dos dois grupos de cultivares demonstram a possibilidade de analisar todas as cultivares em uma única regressão. As estimativas da inclinação da regressão, intercepto e coeficientes de determinação foram, respectivamente, $2,24 \%,-138,82 \%$ e $88,59 \%$ com a consideração de todos os genótipos (Tabela 2). As inclinações com sinais positivos indicam que a diminuição da precipitação acumulada, ou a ocorrência de deficiência hídrica diminui a necessidade térmica em graus-dia para completar o estádio de chumbinho, ou seja, inicia mais rapidamente o estádio de expansão. As estimativas do intercepto e da inclinação da reta da regressão estimam que a cada $100 \mathrm{~mm}$ a mais de precipitação, ocorre um acréscimo de necessidade de soma térmica de 224 graus-dia. O coeficiente de determinação indica que $88 \%$ da variação existente entre as floradas, com relação a graus-dia, são explicadas pela variação em disponibilidade hídrica.
Durante o estádio de chumbinho ocorre o início da formação de importantes tecidos, após a fecundação, como o crescimento do perisperma, os integumentos e o início da formação do embrião, que vai se desenvolver em endosperma, bem como, paredes celulares do futuro pericarpo (De-Castro e Marraccini, 2006). Portanto, uma aceleração acentuada durante este estádio, devido à ocorrência de deficiência hídrica, pode afetar a formação correta das sementes, com conseqüências em produtividade e problemas de germinação.

O segundo estádio fenológico após a florada é a expansão dos frutos, no qual não foi possível detectar diferenças significativas entre os genótipos para número de dias, graus-dia, precipitação pluvial acumulada e temperatura média no período (Tabela 4).

Tabela 3. Comparação entre médias para número de dias (D/C), graus-dia (GD/C), precipitação pluvial (P/C) e temperatura (T/C) durante o estádio de chumbinho em 16 genótipos de café arábica. Anos agrícolas de 2004/2005 e 2005/2006. IAPAR, Londrina (PR).

\begin{tabular}{|c|c|c|c|c|}
\hline Genótipos $\left({ }^{1}\right)$ & $\mathrm{D} / \mathrm{C}$ & $\mathrm{GD} / \mathrm{C}$ & $\mathrm{P} / \mathrm{C}$ & $\mathrm{T} / \mathrm{C}$ \\
\hline Icatu Precoce IAC 3282 & 63,6 a & 759,1 a & 390,8 a & 22,24 a \\
\hline Mundo Novo IAC 464-12 & 62,0 a & 737,2 a & 386,6 a & 22,20 a \\
\hline IAPAR 59 & 63,6 a & 759,1 a & 390,8 a & 22,24 a \\
\hline Rume Sudam IAC 1139 & $69,2 \mathrm{~b}$ & 829,9 b & $438,9 \mathrm{~b}$ & 22,25 a \\
\hline Costa Rica 95 T-8667 & $69,2 \mathrm{~b}$ & 829,9 b & $438,9 \mathrm{~b}$ & 22,25 a \\
\hline Catucai 785-15 & 65,4 a & 778,9 a & $419,3 \mathrm{~b}$ & 22,18 a \\
\hline Catucaiaçu & $69,2 \mathrm{~b}$ & 829,9 b & $438,9 \mathrm{~b}$ & 22,25 a \\
\hline Villa Sarchí ICAFÉ & $71,8 \mathrm{~b}$ & $869,3 \mathrm{~b}$ & $439,7 \mathrm{~b}$ & 22,31 a \\
\hline Rubi MG1192 & $72,0 \mathrm{~b}$ & $861,4 \mathrm{~b}$ & $454,5 \mathrm{~b}$ & 22,27 a \\
\hline Ouro Verde IAC H5010-5 & $69,2 \mathrm{~b}$ & 829,9 b & $438,9 \mathrm{~b}$ & 22,25 a \\
\hline Sarchímor IAPAR 88480-8 & $71,8 \mathrm{~b}$ & $869,3 \mathrm{~b}$ & $439,7 \mathrm{~b}$ & 22,31 a \\
\hline Tupi IAC 1669-33 & $71,8 \mathrm{~b}$ & 869,3 b & $439,7 \quad b$ & 22,31 a \\
\hline Catuaí Vermelho IAC 99 & $71,8 \mathrm{~b}$ & $869,3 \mathrm{~b}$ & $439,7 \mathrm{~b}$ & 22,31 a \\
\hline Catucai vermelho 4-79 & $69,2 \mathrm{~b}$ & 829,9 b & $438,9 \mathrm{~b}$ & 22,25 a \\
\hline Sarchímor E9702 III-1-9 & $69,2 \mathrm{~b}$ & 829,9 b & $438,9 \mathrm{~b}$ & 22,25 a \\
\hline Obatã IAC 1669-20 & $74,6 \mathrm{~b}$ & $900,7 \mathrm{~b}$ & $478,7 \mathrm{~b}$ & 22,41 a \\
\hline Média $\pm \mathrm{DP}\left({ }^{2}\right)$ & $68,97 \pm 27,5$ & $828,3 \pm 346,8$ & $432,1 \pm 146,0$ & $22,27 \pm 0,99$ \\
\hline Média $\pm \mathrm{DPa}\left({ }^{3}\right)$ & $63,65 \pm 23,5$ & $758,6 \pm 285,3$ & $389,4 \pm 130,8$ & $22,27 \pm 0,99$ \\
\hline Média $\pm \mathrm{DPb}\left({ }^{4}\right)$ & $71,08 \pm 25,8$ & $851,6 \pm 328,3$ & $441,9 \pm 133,9$ & - \\
\hline Média \pm DPc $\left({ }^{5}\right)$ & - & - & - & - \\
\hline $\mathrm{CVe}(\%)$ & 8,12 & 8,94 & 8,02 & 0,46 \\
\hline
\end{tabular}

(1) Médias dos genótipos seguidas pela mesma letra não diferem entre si pelo método de Scott e Knott a $5 \%$ de probabilidade. DP = desviopadrão; $\mathrm{CV}_{\mathrm{e}}=$ coeficiente de variação experimental. $\left({ }^{2}\right)$ Média e desvio-padrão geral. $\left({ }^{3}\right)$ Média e desvio-padrão dos genótipos classificados com letra a. $\left({ }^{4}\right)$ Média e desvio-padrão dos genótipos classificados com letra b. $\left({ }^{5}\right)$ Média e desvio-padrão dos genótipos classificados com letra c. 
Tabela 4. Comparação entre médias para número de dias (D/E), graus-dia (GD/E), precipitação pluvial (P/E) e temperatura (T/E) durante o estádio de expansão em 16 genótipos de café arábica. Anos agrícolas de 2004/2005 e 2005/2006. IAPAR, Londrina (PR).

\begin{tabular}{|c|c|c|c|c|}
\hline Genótipos $\left({ }^{1}\right)$ & $\mathrm{D} / \mathrm{E}$ & GD/E & $\mathrm{P} / \mathrm{E}$ & $\mathrm{T} / \mathrm{E}$ \\
\hline Icatu Precoce IAC 3282 & 64,6 a & 852,9 a & 305,8 a & 23,90 a \\
\hline Mundo Novo IAC 464-12 & 63,2 a & 838,8 a & 271,7 a & 24,03 a \\
\hline IAPAR 59 & 64,6 a & 852,9 a & 305,8 a & 23,89 a \\
\hline Rume Sudam IAC 1139 & 64,4 a & 860,1 a & 302,0 a & 24,25 a \\
\hline Costa Rica 95 T-8667 & 67,4 a & 896,1 a & 338,0 a & 24,06 a \\
\hline Catucai 785-15 & 68,2 a & 911,1 a & 321,6 a & 24,18 a \\
\hline Catucaiaçu & 64,8 a & 856,8 a & 337,1 a & 23,97 a \\
\hline Villa Sarchí ICAFÉ & 69,0 a & 913,3 a & 324,9 a & 23,79 a \\
\hline Rubi MG1192 & 74,4 a & 977,9 a & 367,4 a & 23,87 a \\
\hline Ouro Verde IAC H5010-5 & 61,8 a & 820,8 a & 301,2 a & 24,16 a \\
\hline Sarchímor IAPAR 88480-8 & 64,6 a & 850,4 a & 342,8 a & 23,90 a \\
\hline Tupi IAC 1669-33 & 64,8 a & 856,8 a & 337,1 a & 23,95 a \\
\hline Catuaí Vermelho IAC 99 & 74,8 a & 994,1 a & 361,7 a & 24,02 a \\
\hline Catucai vermelho 4-79 & 74,2 a & 987,9 a & 343,7 a & 23,99 a \\
\hline Sarchímor E9702 III-1-9 & 67,2 a & 889,7 a & 353,9 a & 24,08 a \\
\hline Obatã IAC 1669-20 & 67,2 a & 889,7 a & 343,7 a & 24,00 a \\
\hline Média $\pm \mathrm{DP}\left({ }^{2}\right)$ & $67,2 \pm 25,3$ & $890,6 \pm 332,3$ & $328,6 \pm 173,6$ & $24,00 \pm 0,60$ \\
\hline Média $\pm \mathrm{DPa}\left({ }^{3}\right)$ & $67,2 \pm 25,3$ & $890,6 \pm 332,3$ & $328,6 \pm 173,6$ & $24,00 \pm 0,60$ \\
\hline Média $\pm \mathrm{DPb}\left({ }^{4}\right)$ & - & - & - & - \\
\hline Média $\pm \operatorname{DPc}\left({ }^{5}\right)$ & - & - & - & - \\
\hline $\mathrm{CVe}(\%)$ & 14,03 & 14,22 & 20,95 & 1,01 \\
\hline
\end{tabular}

$\left({ }^{1}\right)$ Médias de genótipos seguidas pela mesma letra não diferem entre si pelo método de Scott e Knott a $5 \%$ de probabilidade. DP = desvio padrão; $\mathrm{CV}_{\mathrm{e}}=$ coeficiente de variação experimental. $\left({ }^{2}\right)$ Média e desvio-padrão geral; $\left({ }^{3}\right)$ Média e desvio-padrão dos genótipos classificados com letra a. $\left({ }^{4}\right)$ Média e desvio-padrão dos genótipos classificados com letra b. $\left({ }^{5}\right)$ Média e desvio-padrão dos genótipos classificados com letra c.

O número de dias médio para completar o estádio de expansão foi de $67,2 \pm 25,3$, proporcionando soma térmica de $890,6 \pm 332,3$ grausdia, precipitação pluvial acumulada de $328,65 \pm 173,6$ $\mathrm{mm}$ e temperatura média de $24,00 \pm 0,60^{\circ} \mathrm{C}$ (Tabela 4). Mesmo não sendo detectada diferença significativa entre os genótipos para a duração do estádio de expansão, obteve-se coeficiente de correlação fenotípica significativo entre a soma térmica para este estádio (GD/E) e para completar a maturação plena (GD/F-CE) (Tabela 7), portanto, o estádio de expansão dos frutos influencia na duração do período floradacereja.

Os altos valores de desvios-padrão para as variáveis consideradas durante o estádio de expansão, demonstram a existência de alta variabilidade entre as floradas (Tabela 4). Com a utilização do conceito de graus-dia, pressupõe-se que o número de dias é corrigido de acordo com as variações da temperatura e realizando-se a análise de regressão entre graus-dia e precipitação, referente ao estádio de expansão, consideram-se as principais variáveis climáticas envolvidas na duração de estádios fenológicos de plantas, que são a temperatura do ar e a disponibilidade hídrica. Foi obtida significância $(\mathrm{P}=0,01)$ para a análise de regressão entre graus-dia (GD/E) e precipitação pluvial acumulada (P/E) (Tabela 2). Portanto, a disponibilidade hídrica tem grande influência na duração deste estádio. As estimativas do intercepto e da inclinação da reta de regressão foram, respectivamente, 434,8 e 1,39 (Tabela 2), ou seja, a cada $100 \mathrm{~mm}$ a menos de precipitação ocorre aceleração da duração média desta fase em 139 graus-dia.

Durante o estádio de expansão dos frutos ocorre intensa atividade metabólica, quando o fruto aumenta rapidamente em volume e matéria seca. Este é o período que definirá o tamanho dos grãos ou das sementes, pois, ocorrerá a lignificação do endocarpo definindo o volume máximo que a semente ou grão poderá alcançar (CANNELL, 1985; CAMARGO e CAMARGO, 2001). Portanto, como os cafés sofrem grande influência da precipitação neste período, a ocorrência de deficiências hídricas pode resultar na ocorrência de cafés com peneira baixa, com conseqüências em qualidade e produtividade (CAMARGO e CAMARGO, 2001). 
O estádio de grão verde apresentou variabilidade com a obtenção de diferença significativa entre os genótipos (Tabela 5). O número de dias médio para este estádio foi $67,1 \pm 18,79$, o que gerou uma soma térmica de $842,9 \pm 279,43$ graus-dia, uma precipitação acumulada no período de $243,0 \pm 154,13 \mathrm{~mm}$ e $22,99 \pm$ $1,35^{\circ} \mathrm{C}$ de temperatura. Foi possível separar os genótipos em dois grupos, de acordo com as necessidades térmicas para completar este estádio (Tabela 5).

Esta fase é de grande relevância para a produtividade dos cafeeiros, pois, a granação dos frutos ou a formação dos endospermas torna-se um forte dreno para assimilados e nutrientes (CANNELL, 1985; SALAZARGutièrrez et al., 1994; Arcila-Pulgarín et al., 2002). O conhecimento das diferenças entre as cultivares para completar a granação dos frutos, pode auxiliar na realização de tratos culturais em períodos corretos, principalmente adubação, bastante exigida neste período.
A ordem de classificação das cultivares neste estádio fenológico (Tabela 5) foi bastante concordante com a necessidade térmica para completar a maturação plena (estádio cereja) (Tabela 1). A influência do período de granação dos frutos no ciclo fenológico do cafeeiro foi comprovada pelo coeficiente de correlação positivo e significativo entre a necessidade térmica para completar o estádio de grão verde e para alcançar o estádio de cereja (Tabela 7).

Para a variável precipitação acumulada (P/ GV) durante o estádio de grão verde não foi detectada diferença significativa entre as cultivares, portanto, as cultivares foram separadas com relação aos graus-dia, mesmo com precipitações acumuladas semelhantes (Tabela 5). Existem indicações de que a ocorrência de deficiências hídricas durante este estádio pode acelerar a passagem para o estádio seguinte, e conseqüentemente resultar em maior porcentagem de grãos chochos (CAMARGO e CAMARGO, 2001).

Tabela 5. Comparação entre médias para número de dias (D/GV), graus-dia (GD/GV), precipitação (P/GV) e temperatura (T/GV) durante o estádio de grão-verde em 16 cultivares de café arábica. Anos agrícolas de 2004/2005 e 2005/2006. IAPAR, Londrina (PR)

\begin{tabular}{|c|c|c|c|c|}
\hline Genótipos $\left({ }^{1}\right)$ & $\mathrm{D} / \mathrm{GV}$ & $\mathrm{GD} / \mathrm{GV}$ & $\mathrm{P} / \mathrm{GV}$ & $\mathrm{T} / \mathrm{GV}$ \\
\hline Icatu Precoce IAC 3282 & 51,8 a & 687,4 a & 231,3 a & 23,90 a \\
\hline Mundo Novo IAC 464-12 & 58,4 a & 767,2 a & 270,9 a & 23,59 a \\
\hline IAPAR 59 & 59,6 a & 768,8 a & 260,6 a & 23,40 a \\
\hline Rume Sudam IAC 1139 & 64,4 a & 824,4 a & 262,6 a & 23,35 a \\
\hline Costa Rica 95 T-8667 & 61,4 a & 788,4 a & 226,6 a & 23,38 a \\
\hline Catucai 785-15 & 67,2 a & 853,6 a & 276,9 a & 23,24 a \\
\hline Catucaiaçu & 63,4 a & 778,2 a & 211,1 a & 23,06 a \\
\hline Villa Sarchí ICAFÉ & 59,4 a & 854,4 a & 232,0 a & $22,43 \mathrm{~b}$ \\
\hline Rubi MG1192 & 66,6 a & 826,0 a & 213,2 a & $22,37 \mathrm{~b}$ \\
\hline Ouro Verde IAC H5010-5 & $72,6 \mathrm{~b}$ & $927,4 \mathrm{~b}$ & 263,5 a & 23,31 a \\
\hline Sarchímor IAPAR 88480-8 & $74,2 \mathrm{~b}$ & $930,7 \mathrm{~b}$ & 238,9 a & 23,17 a \\
\hline Tupi IAC 1669-33 & $78,6 \mathrm{~b}$ & $965,9 \mathrm{~b}$ & 257,5 a & 22,95 a \\
\hline Catuaí Vermelho IAC 99 & 67,0 a & 780,8 a & 211,1 a & $22,23 \mathrm{~b}$ \\
\hline Catucai vermelho 4-79 & $70,2 \mathrm{~b}$ & 826,3 a & 240,5 a & $22,70 \mathrm{~b}$ \\
\hline Sarchímor E9702 III-1-9 & $76,0 \mathrm{~b}$ & $921,4 \quad b$ & 222,1 a & $22,41 \mathrm{~b}$ \\
\hline Obatã IAC 1669-20 & 82,8 b & $986,2 \mathrm{~b}$ & 266,8 a & $22,42 \mathrm{~b}$ \\
\hline Média \pm DP $\left({ }^{2}\right)$ & $67,1 \pm 18,79$ & $842,9 \pm 279,4$ & $243,0 \pm 154,13$ & $22,99 \pm 1,35$ \\
\hline Média $\pm \mathrm{DPa}\left({ }^{3}\right)$ & $61,9 \pm 18,42$ & $804,6 \pm 267,6$ & $243,0 \pm 154,13$ & $23,17 \pm 1,33$ \\
\hline Média $\pm \mathrm{DPb}\left({ }^{4}\right)$ & $75,73 \pm 17,31$ & $927,3 \pm 262,9$ & - & $-22,71 \pm 1,55$ \\
\hline Média $\pm \operatorname{DPc}\left({ }^{5}\right)$ & - & - & - & - \\
\hline $\mathrm{CVe}(\%)$ & 16,33 & 16,06 & 31,84 & 3,91 \\
\hline
\end{tabular}

(1) Médias de genótipos seguidas pela mesma letra não diferem entre si pelo método de Scott e Knott a $5 \%$ de probabilidade. DP = desvio padrão; $\mathrm{CV}_{\mathrm{e}}=$ coeficiente de variação experimental. $\left({ }^{2}\right)$ Média e desvio-padrão geral; $\left({ }^{3}\right)$ Média e desvio-padrão dos genótipos classificados com letra a. $\left({ }^{4}\right)$ Média e desvio-padrão dos genótipos classificados com letra b. $\left({ }^{5}\right)$ Média e desvio-padrão dos genótipos classificados com letra c. 
Por meio das análises de regressões entre graus-dia (GD/GV) e precipitação pluvial acumulada (P/GV) durante a fase de grão verde, foi possível determinar a influência da disponibilidade hídrica na exigência térmica para este estádio fenológico do café, pois se obteve significância $(P=0,01)$ pelo teste $F$, dentro de cada grupo de cultivares, bem como considerando todas conjuntamente (Tabela 2). As estimativas da inclinação da regressão e do coeficiente de determinação utilizando todas as cultivares na análise foram, respectivamente, de $1,40 \%$ e $55,02 \%$ (Tabela 2). A inclinação com sinal positivo indica que a diminuição da disponibilidade hídrica reduz a necessidade térmica em graus-dia para completar o estádio de grão verde. A ocorrência de deficiências severas poderá acelerar demais este estádio e resultar em formação de frutos chochos, pois não terá ocorrido a formação e o enchimento completo do endosperma.
O intercepto e a inclinação da reta de regressão obtida entre graus-dia e a precipitação acumulada, para o estádio de grão verde (Tabela 2), determinam uma necessidade de 140 graus-dia menor a cada $100 \mathrm{~mm}$ a menos de precipitação pluvial.

O estádio de verde cana é mais curto que os demais e indica o início da maturação dos frutos. Não há relatos que variáveis climáticas afetam este estádio e esteja relacionado a algum problema de qualidade de grãos ou de bebida. Porém, é uma fase de transição do grão verde para o estádio cereja que pode ser abreviada ou retardada, dependendo das condições climáticas, o que afeta o início da colheita. Foram obtidos para este estádio, 22,15 \pm 7,7 dias, 216,9 \pm 79,1 graus-dia, precipitação pluvial acumulada de $60,7 \pm 49,9 \mathrm{~mm}$ e temperatura média de $20,72 \pm 1,84$ ${ }^{\circ} \mathrm{C}$ (Tabela 6).

Tabela 6. Comparação entre médias para número de dias (D/VC), graus-dia (GD/VC), precipitação pluvial (P/VC) e temperatura (T/VC) durante o estádio de verde-cana em 16 cultivares de café arábica. Anos agrícolas de 2004/2005 e 2005/2006. IAPAR, Londrina (PR)

\begin{tabular}{|c|c|c|c|c|}
\hline Genótipos $\left({ }^{1}\right)$ & $\mathrm{D} / \mathrm{VC}$ & GD/VC & $\mathrm{P} / \mathrm{VC}$ & $\mathrm{T} / \mathrm{VC}$ \\
\hline Icatu Precoce IAC 3282 & 21,6 a & 245,5 a & 76,62 a & 22,68 a \\
\hline Mundo Novo IAC 464-12 & 20,4 a & 236,9 a & 64,52 a & 23,00 a \\
\hline IAPAR 59 & 19,4 a & 227,8 a & 56,52 a & 22,42 a \\
\hline Rume Sudam IAC 1139 & 18,6 a & 192,8 a & 50,92 a & $21,21 \mathrm{~b}$ \\
\hline Costa Rica 95 T-8667 & 18,6 a & 192,8 a & 50,92 a & $21,21 b$ \\
\hline Catucai 785-15 & 22,8 a & 218,5 a & 38,16 a & $20,60 \mathrm{c}$ \\
\hline Catucaiaçu & 29,6 a & 314,3 a & 73,88 a & $21,25 \mathrm{~b}$ \\
\hline Villa Sarchí ICAFÉ & 20,0 a & 150,3 a & 52,38 a & $20,16 \mathrm{c}$ \\
\hline Rubi MG1192 & 17,4 a & 160,7 a & 42,76 a & $20,24 \mathrm{c}$ \\
\hline Ouro Verde IAC H5010-5 & 25,4 a & 225,5 a & 61,56 a & $19,68 \mathrm{c}$ \\
\hline Sarchímor IAPAR 88480-8 & 22,2 a & 194,6 a & 79,22 a & $19,27 \mathrm{c}$ \\
\hline Tupi IAC 1669-33 & 19,0 a & 166,9 a & 69,86 a & $19,20 \mathrm{c}$ \\
\hline Catuaí Vermelho IAC 99 & 24,0 a & 229,6 a & 65,26 a & $20,65 c$ \\
\hline Catucai vermelho 4-79 & 26,2 a & 273,2 a & 58,82 a & $19,95 \mathrm{c}$ \\
\hline Sarchímor E9702 III-1-9 & 27,4 a & 252,4 a & 66,98 a & $20,55 \mathrm{c}$ \\
\hline Obatã IAC 1669-20 & 21,8 a & 189,5 a & 61,56 a & $19,52 \mathrm{c}$ \\
\hline Média \pm DP $\left({ }^{2}\right)$ & $22,1 \pm 7,7$ & $216,9 \pm 79,1$ & $60,7 \pm 49,9$ & $20,72 \pm 1,84$ \\
\hline Média $\pm \mathrm{DPa}\left({ }^{3}\right)$ & $22,1 \pm 7,7$ & $216,9 \pm 79,1$ & $60,7 \pm 49,9$ & $22,70 \pm 1,67$ \\
\hline Média $\pm \mathrm{DPb}\left({ }^{4}\right)$ & - & - & - & $21,22 \pm 1,83$ \\
\hline Média \pm DPc (5) & - & - & - & - \\
\hline $\mathrm{CV}_{\mathrm{e}}(\%)$ & 34,66 & 35,93 & 67,86 & 5,81 \\
\hline
\end{tabular}

(1) Médias de genótipos seguidas pela mesma letra não diferem entre si pelo método de Scott e Knott a $5 \%$ de probabilidade. DP $=$ desvio padrão; $\mathrm{CV}_{\mathrm{e}}$ = coeficiente de variação experimental. $\left({ }^{2}\right)$ Média e desvio-padrão geral; $\left(^{3}\right)$ Média e desvio-padrão dos genótipos classificados com letra a. $\left({ }^{4}\right)$ Média e desvio-padrão dos genótipos classificados com letra b. $\left({ }^{5}\right)$ Média e desvio-padrão dos genótipos classificados com letra c. 
Não foi possível detectar diferença significativa entre os genótipos para as variáveis consideradas, exceto para temperatura média durante o estádio de grão verde (Tabela 6). Esta variação entre os genótipos para a variável temperatura pode ser explicada pelo estádio, em cada cultivar, ter ocorrido em épocas diferentes do ano, já que os genótipos mais tardios apresentaram temperaturas menores que os mais precoces (Tabela 6).

Os desvios-padrão para o estádio de verde cana indicam a existência de alta variabilidade entre as floradas (Tabela 6). As análises de regressão realizadas a partir desta variabilidade, entre a soma térmica em graus-dia $(\mathrm{GD} / \mathrm{C})$ e a precipitação pluvial $(\mathrm{P} / \mathrm{C})$ acumulada apresentaram significância $(\mathrm{P}=0,01)$ (Tabela 6). Portanto, existe influência da disponibilidade hídrica para completar o estádio de verde cana. As estimativas do intercepto, da inclinação da regressão e do coeficiente de determinação (Tabela 2) indicam que a diminuição da precipitação acumulada proporciona menor necessidade térmica em graus-dia para completar o estádio de verde cana, ou seja, inicia mais rapidamente o estádio de cereja e, consequentemente, a colheita.

Para o estádio de verde cana, a soma térmica em graus-dia (GD/VC) não resultou em correlação significativa com os graus-dia para o estádio cereja (GD/F-CE) (Tabela 7). Portanto, dos quatro estádios que compõem a duração do ciclo fenológico reprodutivo do cafeeiro arábica, ou seja, da florada até o estádio de cereja, o verde cana é o único que não influencia na duração total, considerando a exigência térmica em graus-dia.

Tabela 7. Estimativas dos coeficientes de correlação de Pearson entre graus-dia para os estádios de chumbinho (GD/ C), expansão (GD/E), grão verde (GD/GV), verde cana $(G D / V C)$ e da florada até o estádio de cereja (D/F-CE). Anos agrícolas de2004/2005 e 2005/2006. IAPAR, Londrina (PR)

\begin{tabular}{|c|c|c|c|c|c|}
\hline & GD/F-CE & GD/C & GD/E & GD/GV & $\mathrm{GD} / \mathrm{VC}$ \\
\hline GD/F-CE & - & - & - & - & - \\
\hline GD/C & 0,8189 ** & - & - & - & - \\
\hline GD/E & 0,4333 * & $0,3608^{\mathrm{ns}}$ & $\begin{array}{c}- \\
-01151 \\
n s\end{array}$ & - & - \\
\hline $\mathrm{GD} / \mathrm{VC}$ & $-0,0934^{\mathrm{ns}}$ & $-0,4382$ * & $-0,0801^{\mathrm{ns}}$ & $-0,3951^{\mathrm{ns}}$ & - \\
\hline
\end{tabular}

**, *: significativo a $1 \%$ e $5 \%$ de probabilidade respectivamente, pelo teste t. ${ }^{\text {ns: }}$ não significativo.

O conhecimento das interações dos estádios fenológicos com variáveis climáticas e as exigências térmicas para a maturação dos frutos nas cultivares de café, classificando-as em grupos de maturação, levará à maior eficiência na organização de tratos culturais e de colheita, bem como, menor risco com a atividade devido a melhor locação das cultivares regionalmente e na propriedade.

Na regionalização das cultivares, de acordo com a época de maturação, as precoces são indicadas para regiões mais frias, onde a ocorrência de geadas é mais freqüente, evitando-se os danos em frutos verdes. Já as mais tardias são preferidas em regiões mais quentes, devido a aceleração que temperaturas altas provocam no desenvolvimento dos frutos, podendo formar frutos mal granados e de peneira baixa. De acordo com a recomendação topoclimática na propriedade, as cultivares precoces são indicadas para locais com maior freqüência de geadas e as mais tardias para os locais menos sujeitos, evitando danos nos frutos verdes e diminuindo assim a instabilidade na atividade.
A caracterização das cultivares em exigências térmicas, com uma disponibilidade hídrica conhecida, levará a uma uniformização das classificações em grupos de maturação, proporcionando aos técnicos extensionistas maior confiança na recomendação da tecnologia de escalonamento da colheita.

\section{CONCLUSÕES}

1. Foi possível caracterizar de acordo com a exigência térmica as cultivares de café arábica utilizadas nesta pesquisa, em grupos de maturação precoce, médio e tardio, com disponibilidade hídrica semelhante entre elas.

2. As cultivares 'Icatu Precoce IAC 3282', 'Mundo Novo IAC 464-12', 'IAPAR 59', 'Rume Sudam IAC1139' e 'Costa Rica 95' foram classificadas como cultivares precoces.

3. O grupo de maturação média é formado pelas cultivares Catucai 785-15, Catucaiaçu, Villa Sarchí ICAFÉ, Rubi MG1192 e Ouro Verde IAC H5010-5. 
4. As cultivares classificadas como tardias foram 'Obatã IAC 1669-20', Sarchímor IAPAR884808, Tupi IAC 1669-33, 'Catuaí Vermelho IAC 99', 'Catucai vermelho 4-79 4-79' e 'Sarchímor E9702 III$1-9$ '.

5. Todos os estádios fenológicos do café, exceto o verde cana, são influenciados pela temperatura e contribuem para determinar a exigência térmica para atingir a maturação dos frutos.

6. Todos os estádios fenológicos de desenvolvimento dos frutos (chumbinho, expansão, grão verde, verde cana) e a duração da florada até o estádio cereja, sofrem forte influência da disponibilidade hídrica na exigência térmica, acelerando a maturação dos frutos na ocorrência de deficiências hídricas.

7. Apenas o somatório de graus-dia não é suficiente para caracterizar a maturação dos frutos em cultivares de café arábica, sendo necessário também considerar a disponibilidade hídrica.

\section{AGRADECIMENTOS}

À equipe de Melhoramento de Café do Instituto Agronômico do Paraná, pelo auxílio na execução dos trabalhos, ao Programa de PósGraduação em Agronomia da Universidade Estadual de Londrina e ao Consórcio Brasileiro de Pesquisa e Desenvolvimento de Café e à CAPES pelo auxilio financeiro.

\section{REFERENCIAS}

ARCILA-PULGARÍN, J.; BUHR, L.; BLEIHOLDER, H.; HACK, H.; MEIER, U.; WICKE, H. Application of the extended BBCH scale for the description of the growth stages of coffee (Coffea spp.). Annals of Applied Biology, v. 141, p.19-27, 2002.

AGUIAR, A.T.E.; GURREIRO-FILHO, O.; MALUF, M.P.; GALLO, P.B.; FAZUOLI, L.C. Caracterização de cultivares de Coffea arabica mediante utilização de descritores mínimos. Bragantia, Campinas, v.63, n.2, p.179-192, 2004.

BRUNINI, O., LISBÃO, R.S., BERNARDI, J.B. Temperatura-base para alface "Withe Boston", em um sistema de unidades térmicas. Bragantia, Campinas, v. 35, p. 214-219, 1976.

CAMARGO, A.P.; CAMARGO, M.B.P. Definição e esquematização das fases fenológicas do cafeeiro arábica nas condições tropicais do Brasil. Bragantia, Campinas, v.60,n.1, p.65-68, 2001.

CANNEL, M.G.R. Physiology of the coffee crop. In:CLIFFORD, M.N.; WILSON, K.C. Coffee: botany, biochemistry and production of beans and beaverage. London: Croom Helm, 1985. p.108-134.
CARVALHO, A.; MEDINA-FILHO, H. P.; FAZUOLI, L. C.; GUERREIRO FILHO, O.; LIMA, M..M.A. Aspectos genéticos do cafeeiro. Revista Brasileira de Genética, Ribeirão Preto, v.14, n.1, p.135-183, 1991.

CRUZ, C.D. Programa GENES - versão Windows. Viçosa: UFV, 2001. 642p.

CRUZ, C.D. Programa GENES: Estatística experimental e matrizes. Viçosa: UFV, 2006. 285p.

DE CASTRO, R.D.; MARRACCINI, P. Cytology, biochemistry and molecular changes during coffee fruit development. Brazilian Journal of Plant Physiology, v.18, n.1, p.175-199, 2006.

FAZUOLI, L.C.; MEDINA-FILHO, H.P.; GONÇALVES, W.; GUERREIRO FILHO, O.; SILVAROLA, M. B. Melhoramento do Cafeeiro: variedades tipo arábica obtidas no Instituto Agronômico de Campinas. In: ZAMBOLIM, L. (Ed.). O estado da arte de tecnologias na produção de café. Viçosa: UFV, 2002. p. $163-216$.

FERRÃO, M.A. G.; FONSECA, A. F. A.; FERRÃO, R. G.; ROCHA, A. C.; CELIN, E. Avaliação de progênies e cultivares de Coffea arabica no estado do Espírito Santo. In: SIMPÓSIO DE PESQUISA DOS CAFÉS DO BRASIL, 2, Vitória, ES, 2001. Anais... Brasília: EMBRAPA/CNP\&D-Café, 2001. p. 1272-1278. CDROM.

GARÇON, C. L. P.; BARROS, U. V.; MATIELO, J. B. Diferença na maturação dos frutos entre variedades e linhagens de Coffea arabica, na região da Zona da Mata de Minas Gerais. In: SIMPÓSIO DE PESQUISA DOS CAFÉS DO BRASIL, 2., Vitória, ES, 2001. Anais... Brasília: EMBRAPA/CNP\&D-Café, 2001. p. 100-108. CD-ROM.

IAFFE, A., PINTO, H., ARRUDA, F.B, QUAGLIA, L, SAKAI, E., PIRES, R.C.M., ASSAD, E. Estimativa de temperatura-base e graus-dia com correção pelo fotoperíodo do florescimento à colheita de café em Campinas, SP. In: SIMPÓSIO DE PESQUISA DOS CAFÉS DO BRASIL, II, Vitória, 2002. Resumos... Brasília: EMBRAPA-CAFÉ, 2001. 575-581.

INSTITUTO TECNOLÓGICO SIMEPAR - SIMEPAR. Dados Meteorológicos. Disponível em: <http://www.simepar.br> Acesso em: 05 set. 2005.

JARAMILLO, A.R.; GUZMAN, O.M. Relación entre la temperatura y el crecimiento de Coffea arabica L. var Caturra. Cenicafe, San Jose, v.35(3), p.57-65, 1984.

MATIELO, J. B.; ALMEIDA, S. R. Indicação de variedades resistentes à ferrugem, desenvolvidas pelo IBC e MA/ PROCAFÉ de acordo com a época de maturação dos frutos. In: CONGRESSO BRASILEIRO DE PESQUISAS CAFEEIRAS, 27. 2001, Uberaba, MG, Anais... Rio de Janeiro: PROCAFÉ/ CNP\&D - Café, 2001. p. 12-13.

MORAIS, H.; CARAMORI, P.H.; KOGUISHI, M.S.; RIBEIRO, A..M. de A. Caracterização das fases do desenvolvimento reprodutivo do cafeeiro IAPAR 59. In: CONGRESSO BRASILEIRO DE AGROMETEOROLOGIA, 14., 2005, Campinas, SP, Anais... Campinas, 2005. CD-Rom. 
PEREIRA, A.R., ANGELOCCI, L.R., SENTELHAS, P.C., Agrometeorologia: fundamentos e aplicações práticas. Guaíba:Agropecuária, 2002. 478 p.

PEREIRA, A. A.; MOURA, W. M.; ZAMBOLIM, L.; SAKIYAMA, N. S.; CHAVES, G. M. Melhoramento genético do Cafeeiro no Estado de Minas Gerais - cultivares lançados e em fase de obtenção. In: ZAMBOLIM, L. (Ed.). O estado da arte de tecnologias na produção de café. UFV, 2002, p. 253-296.

PEZZOPANE, J.R M.; PEDRO-JUNIOR, M..J.; THOMAZIELLO, R.A.; PAES DE CAMARGO, M.B. Escala para a avaliação de estádios fenológicos do cafeeiro arábica. Bragantia, Campinas, v.62,n.3, p.499-505, 2003.

PEZZOPANE, J.R.M.; PEDRO JUNIOR, M.J.; PAES DE CAMARGO, M.B.; FAZUOLI, L.C. Temperatura-Base e grausdia com correção pela disponibilidade hídrica para o cafeeiro 'Mundo Novo' no período florescimento-colheita. In: CONGRESSO BRASILEIRO DE AGROMETEOROLOGIA, 14., 2005, Campinas, SP. Anais... Campinas, 2005. CD-Rom.

SALAZAR-GUTIÉRREZ; M.R.; CHAVES-CORDOBA, B.; RIAÑO-HERRERA， N.M.; ARCILA-PULGARÍN， J.; JARAMILLO-ROBLEDO, A. Crescimiento Del fruto de café Coffea arabica L. var Colômbia. Cenicafé, San Jose, v. 45(2), p.41-50, 1994.

SERA, T.; ALTEIA, M. Z.; PETEK, M.R. Melhoramento do Cafeeiro: variedades melhoradas no Instituto Agronômico do Paraná (IAPAR). In: ZAMBOLIM. L. (Ed.). O estado da arte de tecnologias na produção de café. Viçosa: UFV, 2002. p. 217251.

SERA, T.; GUERREIRO, A. Diversificação varietal por maturação. In: SIMPÓSIO INTERNACIONAL SOBRE CAFÉ ADENSADO. Londrina, PR, 1994. Resumos... Londrina: IAPAR, 1994, p.37.

SIQUEIRA, R.; CARAMORI, P.H.; MANETTI-FILHO, J. Maturação dos frutos de três cultivares de cafeeiros em Londrina, PR. Pesquisa Agropecuária Brasileira, Brasília, v. 20, n.12, p.1373-1379, 1985. 